\title{
Ductile Fracture Behaviour of Hot Isostatically Pressed Inconel 690 Superalloy
}

\begin{abstract}
A.J. COOPER, W.J. BRAYSHAW, and A.H. SHERRY
Herein we assess the differences in Charpy impact behavior between Hot Isostatically Pressed and forged Inconel 690 alloy over the temperature range of $300{ }^{\circ} \mathrm{C}$ to $-196{ }^{\circ} \mathrm{C}$. The impact toughness of forged 690 exhibited a relatively small temperature dependence, with a maximum difference of $c a .40 \mathrm{~J}$ measured between $300{ }^{\circ} \mathrm{C}$ and $-196^{\circ} \mathrm{C}$, whereas the HIP'd alloy exhibited a difference of approximately double that of the forged alloy over the same temperature range. We have conducted Charpy impact testing, tensile testing, and metallographic analyses on the as-received materials as well as fractography of the failed Charpy specimens in order to understand the mechanisms that cause the observed differences in material fracture properties. The work supports a recent series of studies which assess differences in fundamental fracture behavior between Hot Isostatically Pressed and forged austenitic stainless steel materials of equivalent grades, and the results obtained in this study are compared to those of the previous stainless steel investigations to paint a more general picture of the comparisons between HIP $v s$ forged material fracture behavior. Inconel 690 was selected in this study since previous studies were unable to completely omit the effects of strain-induced martensitic transformation at the tip of the Chary V-notch from the fracture mechanism; Inconel 690 is unable to undergo strain-induced martensitic transformation due to the alloy's high nickel content, thereby providing a sister study with the omission of any martensitic transformation effects on ductile fracture behavior.
\end{abstract}

https://doi.org/10.1007/s11661-017-4465-3

(c) The Author(s) 2018. This article is an open access publication

\section{INTRODUCTION}

HoT isostatic pressing (HIP), a form of near-net shape (NNS) manufacture, is the consolidation of metal alloy powder in a mold under high temperature and pressure and has been shown to be effective for producing complex geometry components without the need for welds; thus reducing costs, accelerating manufacturing time, and improving performance..$^{[1,2]}$

The advantages of HIP are well documented, ${ }^{[3-6]}$ the most significant being HIP's ability to produce components with exceedingly complex geometries that do not require subsequent machining/welding procedures on the manufactured component. ${ }^{[4]}$ Through the elimination of welded joints, HIP can produce components exhibiting homogenous metallurgy; omitting common issues associated with problematic welded components

A.J. COOPER and W.J. BRAYSHAW are with the School of Materials, University of Manchester, Oxford Road, M13 9PL, UK. Contact e-mail: adam.cooper@manchester.ac.uk A.H. SHERRY is with the School of Materials, University of Manchester and also with the National Nuclear Laboratory, Birchwood Park, Warrington, WA3 6AE, UK.

Manuscript submitted November 10, 2017.

Article published online January 18, 2018 such as hot cracking, heat-affected zones, and induced residual stresses. ${ }^{[8-10]}$ The lack of heat-affected zones and lower residual stresses as a result of the HIP diffusion bonding could enhance resistance to environmentally assisted cracking (EAC). ${ }^{[1,12]}$ Furthermore, the ability to completely avoid welding and subsequent machining not only reduces production lead times, costs, and volume of wasted material, but also eliminates significant expenses associated with costly manufacture and through-life weld inspection procedures. HIP's finer and isotropic microstructure improves strength and aids non-destructive examination, ${ }^{[1,2]}$ and HIP produces isotropic and homogeneous materials that display microstructures with little-to-no directionality and uniform material properties throughout. Finally, HIP produces material with a comparatively smaller grain size than that of forgings and castings, which not only improves the yield strength and ultimate tensile strength, but also lends itself to easier inspection view non-destructive examination techniques. ${ }^{[13]}$

Because of these advantages, there have been increased efforts to demonstrate that components produced by HIP have equivalent or better material properties than those of equivalently graded forged materials, driven by the more demanding levels of regulatory control associated with the nuclear industry, 
to which HIP technology remains to make an impact. There remain real knowledge gaps attached to HIP technology however, highlighted recently by studies on the microstructural development during HIP $^{[14]}$ and the effects of oxygen on material performance, which causes subtle differences in fracture behavior of equivalently graded HIP and forged austenitic stainless steel. ${ }^{[15-18]}$ Powder surface oxidation is difficult to avoid during powder storage and handling, and this surface oxygen is thought to manifest itself in the form of closely spaced non-metallic oxides during the HIP process, and these affect the ductile failure mechanism behavior by acting as initiation sites for the nucleation, growth, and coalescence of voids during plastic deformation. The smaller average interspatial particle distance of oxide inclusions in the HIP microstructure results in smaller radii over which ductile voids are required to grow in order to coalesce with neighboring voids, thus permitting failure at lower levels of plastic strain. Thus, it was shown that the impact toughness was governed by the concentration of oxygen (and oxide inclusions) remaining in the austenite matrix.

However, austenitic stainless steel undergoes strain-induced martensitic transformation at the tip of the Charpy $\mathrm{V}$-notch at temperatures lower than ambient temperature, where the difference in fracture behavior is greatest. Although our previous work showed that the degree of martensitic transformation at the tip of the Charpy V-notch in both HIP and forged 304L stainless steel occurs on comparable scales, this does not completely eliminate martensitic transformation from playing a role in the ductile fracture mechanism and effects on impact toughness. In order to categorically eliminate the effects of strain-induced martensitic transformation on the observed reduction in impact toughness at cryogenic temperatures (where the greatest degree of martensite transformation occurs), we have performed similar testing and analyses on a material that does not undergo martensitic transformation: Inconel grade 690 superalloy. Because nickel acts as a FCC stabilizer through lowering the $M_{\mathrm{s}}$ temperature, the $59 \mathrm{wt}$ pct nickel content in Inconel 690 is sufficiently high to completely prevent strain-induced martensitic transformation. ${ }^{[19]}$
It has been shown ${ }^{[20]}$ that the yield strength and ultimate tensile strength of HIP'd Inconel 718 are independent of the material's oxygen content in the range of 25 to $850{ }^{\circ} \mathrm{C}$, and although the ductility is insensitive to oxygen content at room temperature, it decreases significantly with increasing oxygen content at elevated testing temperatures. However, to our knowledge no comparative study has hitherto been reported on the Charpy impact toughness fracture behavior between equivalently graded HIP'd and forged Inconel superalloy. We present Charpy impact toughness results, as well as metallographic and fractographic assessments in order to characterize the difference in fracture behavior between HIP'd and forged Inconel 690 where the only significant chemical difference between the two materials is the oxygen and nitrogen concentrations and grain size, and compare these to the results obtained from the austenitic stainless steel studies we have reported on previously. ${ }^{[15,16]}$

\section{EXPERIMENTAL}

Testing was performed on HIP'd Inconel 690 (HIP690) and forged Inconel 690 (F690) superalloy. HIP'd 690 material was supplied by The Electric Power Research Institute (EPRI, USA), and forged 690 alloy by Aubert \& Duval, Les Ancizes, France. HIP690 was tested in the as-HIP'd condition, where grade 690 powder was HIP'd at $1120{ }^{\circ} \mathrm{C}$ and $103 \mathrm{MPa}$, and no heat treatment was performed. Forged 690 was annealed at $1040{ }^{\circ} \mathrm{C}$ for several hours.

Table I shows the chemical compositions of the two materials studied, and the specification for Inconel 690, as stated on the material certificate for F690, is also tabulated. Both of the materials are within specification according to ASTM B168-11. ${ }^{[21]}$ The oxygen concentration is not usually specified on materials' certificates; however, it is clear that the oxygen content in the HIP690 is over an order of magnitude greater than that of F690. This observation was also made in previous stainless steel studies. ${ }^{[15,16]}$ Grain size measurements were conducted in accordance with ASTM E112-96, ${ }^{[22]}$ and measured as $28 \mu \mathrm{m} \quad(\mathrm{SD}=5.6)$ and $67 \mu \mathrm{m}$

Table I. Chemical Composition

\begin{tabular}{|c|c|c|c|c|c|c|c|c|}
\hline Element/Wt Pct & $\mathrm{C}$ & $\mathrm{Si}$ & $\mathrm{Mn}$ & $\mathrm{P}$ & $\mathrm{S}$ & $\mathrm{Cr}$ & $\mathrm{Ni}$ & $\mathrm{Cu}$ \\
\hline Spec. & $\leq 0.05$ & $\leq 0.5$ & $\leq 0.5$ & - & $\leq 0.015$ & 27.0 to 31.0 & $\geq 58.00$ & $\leq 0.5$ \\
\hline HIP690 & 0.021 & 0.16 & 0.32 & $<0.001$ & 0.0016 & 28.40 & 58.18 & 0.01 \\
\hline F690 & 0.023 & 0.07 & 0.33 & 0.002 & 0.0005 & 29.49 & 58.44 & $<0.01$ \\
\hline Element/Wt Pct & $\mathrm{Ti}$ & $\mathrm{Fe}$ & $\mathrm{Al}$ & $\mathrm{Co}$ & $\mathrm{B}$ & $\mathrm{Nb}$ & $\mathrm{N}$ & $\mathrm{O}$ \\
\hline Spec. & - & 7.0 to 11.0 & - & - & - & - & - & - \\
\hline HIP690 & 0.01 & 9.66 & 0.02 & $<0.01$ & 0.002 & $<0.01$ & 0.083 & 0.021 \\
\hline F690 & 0.2 & 10.77 & 0.157 & $<0.008$ & $<0.001$ & $<0.01$ & 0.035 & 0.0017 \\
\hline
\end{tabular}


$(\mathrm{SD}=22.7)$ for HIP690 and F690, respectively. Grain size was measured in accordance with ASTM E112-96, ${ }^{[22]}$ where approximately 500 grains were measured in each analysis.

HIP Charpy test specimens were extracted from a HIP'd cylinder and machined in a CR orientation, where $\mathrm{C}$ is the circumferential direction and $\mathrm{R}$ is the radial direction. Forged Charpy specimens were extracted from a rolled plate and machined in a LT orientation, where $\mathrm{L}$ is the longitudinal direction and $\mathrm{T}$ is the transverse direction. Charpy impact testing was performed using an instrumented Charpy testing rig (impact velocity $=5.23 \mathrm{~m} \mathrm{~s}^{-1}$ ) to BS EN ISO 148-1. ${ }^{[23]}$ Specimens prepared for metallurgical analysis were sectioned, mounted, ground, and polished in accordance with the recommended procedures in ASTM practice E3-01. ${ }^{[24]}$

Forged $316 \mathrm{~L}$ tensile test specimens were extracted in the longitudinal (rolling) direction of a forged plate. HIP316L tensile test specimens were extracted in the axial direction of the HIP cylinder. Round bar tension test specimens were machined in accordance with the ASTM E8/E8M-recommended dimensions, with a gage length of $50 \mathrm{~mm}$, a gage diameter of $8 \mathrm{~mm}$, and M12 thread. ${ }^{[25]}$ Tensile testing was conducted in displacement control at a strain rate of $0.5 \mathrm{~min}^{-1}$ at ambient temperature. Three tensile tests were performed for each material and condition, and the values of yield strength, UTS, pct RA, and pct EL were taken as an average of the three tests. Reduction in area (pct RA) was determined using digital Vernier calipers, by measuring the portion of least diameter in the necked region of the failed tensile specimens. EL pct was determined using a 50-mm extensometer placed on the entire length of the gage length, and ELpct taken as the final point in the strain measurement to failure.

To reveal the microstructure and enhance grain boundary contrast, specimens were electro-etched in $10 \mathrm{wt}$ pct oxalic acid at a voltage of $+20 \mathrm{~V}$ for $c a$. 45 seconds. Cryogenic and elevated temperature Charpy testing $\left(-196^{\circ} \mathrm{C}\right.$ to $\left.+300{ }^{\circ} \mathrm{C}\right)$ were performed by either submerging test specimens in liquid nitrogen or placing in a thermally controlled oven for 20 minutes prior to testing. Specimens were transferred to the Charpy test rig within 5 seconds of being removed from the controlled temperature environment. Cryogenic tensile testing conditions were maintained by submerging the test specimen gage length in liquid nitrogen throughout the test.

Metallography and fractography were performed using an FEI Quanta 650 Environmental scanning electron microscope (SEM) and an FEI Sirion SEM, both equipped with field emission guns and electron back-scattered diffraction (EBSD) detectors, and a Hitachi S-3700 scanning electron microscope equipped with Oxford Instruments INCA X-ACT energy-dispersive spectroscopy (EDS) for semi-quantitative chemical analysis. The SEM was performed under vacuum using a $20 \mathrm{kV}$ accelerating voltage and a spot size of $4.0 \mathrm{~nm}$, at a working distance (WD) of approximately $10 \mathrm{~mm}$.

\section{RESULTS}

Figure 1 shows SEM images of (a, c, e) F690 and (b, d, f) HIP 690 microstructures. Metallography was initially performed by electro-etching in oxalic acid, thus revealing the microstructures shown in Figures 1(a) through (d). H690's finer grain size is visible in Figure 1(b) and slight over-etching is visible at the grain boundaries in the form of narrow dark bands, which occurs due to the preferential nature of grain boundaries to anodic dissolution.

Secondary phase particles were clearly present in the F690 microstructure, taking the form of both elongated particles aligned in the rolling direction and square angular particles on the order of $10 \mu \mathrm{m}$, as shown in Figures 1(a) and (e). EDS analysis of these particulates revealed a chemical makeup rich in titanium and nitrogen, indicating titanium nitride (TiN) particles. No other particles were observed in the F690 microstructure. Given that the particles exhibited very similar chemical compositions of titanium and nitrogen, it is unclear why some appeared square and angular, whilst others appeared elongated in the forging direction. It is thought that maybe these particles formed at different stages of manufacture, with the elongated TiN particles forming before forging and the square TiN particles forming afterwards potentially during cooling. The appearance of the finer square-like TiN particles is in agreement with Tan et al. ${ }^{[26]}$ who observed similar particles in Inconel 690 and who were able to show that the particles actually consisted of an $\mathrm{Al}_{2} \mathrm{O}_{3} / \mathrm{MgO}$ nucleus surrounded by a TiN shell; indeed, a dark spherical nucleus on the order of $1 \mu \mathrm{m}$ was also visible within the TiN particles in this work.

In contrast to F690, the HIP690 materials showed little evidence of $\mathrm{TiN}$ inclusions in the microstructure, instead exhibiting a fine distribution of pores in the microstructure. The apparent lack of TiN particles is thought to be related to the much smaller concentration of titanium in the HIP690 chemistry 0.01 cf. 0.2 pct wt (see Table I). From our previous work, ${ }^{[15,16]}$ whereby pores visible in the microstructures of $304 \mathrm{~L}$ and $316 \mathrm{~L}$ were actually the result of oxide inclusions being dislodged from the microstructure during metallographic preparation rather than internal porosity, it was assumed that the same phenomenon was being observed here in HIP690. It is thought that etching encourages the removal of fine particles from the microstructure by attacking the boundary between the particle and the microstructure and thus leaving behind voids in the microstructure.

To minimize the chance of dislodging any particles from the microstructure, metallographic preparation was repeated this time with the omission of the electro-etching stage and using as minimal force as possible during manual polishing. The resulting microstructures are presented in Figures 1(e) and (f), for F690 and HIP690, respectively. HIP690 clearly exhibits a fine distribution of secondary phase particles taking the form of fine spherical particles with sizes on the order of several microns (Figure 1(d)). These parti- 

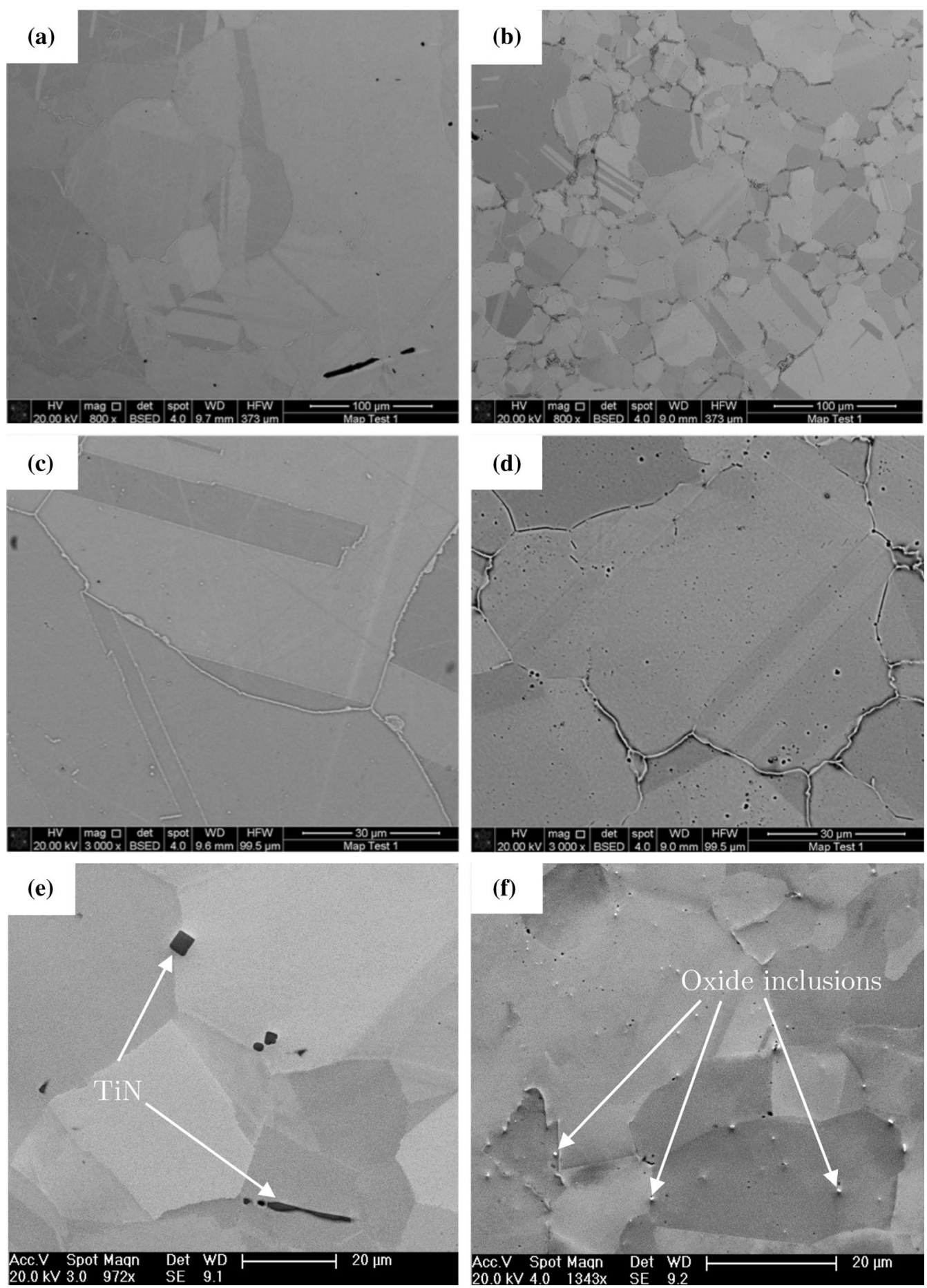

Fig. 1-SEM images showing the microstructures of $(a, c)$ F690 and $(b, d)$ HIP690. The microstructures in $(e)$ and $(f)$ have been prepared without etching and a minimal amount of force during polishing to reveal secondary particles.

cles were smaller than the X-ray sample area recorded by the EDS detector, thus making chemical analysis challenging since excluding the surrounding material from the analysis was not possible. Nonetheless, analysis typically revealed relatively prominent peaks in the region of oxygen, aluminum, silicon, sulfur, and manganese, indicating potential candidates as a mixture of $\mathrm{Al}_{2} \mathrm{O}_{3}, \mathrm{MgO}, \mathrm{SiO}_{2}$, and $\mathrm{MnS}$ inclusions in nature. These peaks were not visible when performing EDS on a region of material that contained no observable particles. These oxide particles are thought to arise as a result of powder surface oxidation during powder handling and storage, which is reflected in the higher oxygen concentration in the bulk HIP materials (Table I). HIP690's higher S (0.0016 cf. 0.0005) and Si (0.16 cf. 0.07 ) content might also contribute to the formation of 
the observed oxide and sulfide particles in the microstructure.

Charpy impact testing data are presented in Figure 2. F690 exhibits a slight temperature effect (gradient $=0.068$ ), with a total decrease in impact toughness of approximately $40 \mathrm{~J}$ over the entire test temperature range. Since martensite cannot play a role in embrittling the material, this gradual reduction in toughness is attributed to a material's reduced ability to absorb energy via plastic deformation at cryogenic temperatures than at elevated temperatures, since dislocation movement on slip planes is hindered by the reduction in available energy. HIP690 follows a similar trend, but the

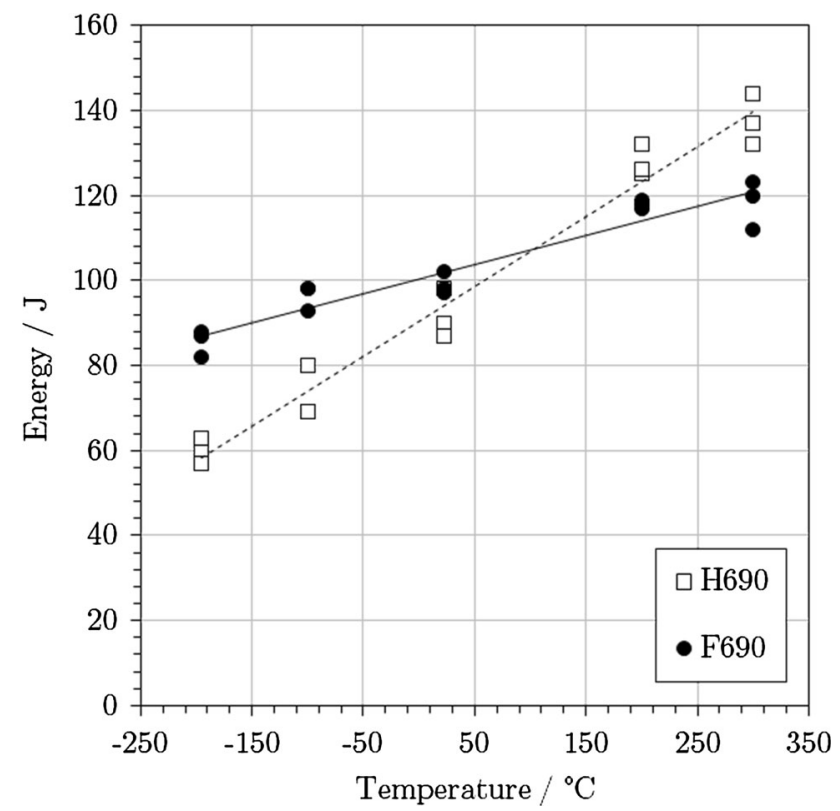

Fig. 2-Charpy impact toughness data for HIP and forged Inconel 690 materials. gradient is nearly double that of the forged 690 data (0.164 cf. 0.068), resulting in HIP690 exhibiting an enhanced impact toughness by $c a$. $30 \mathrm{~J}$ over F690 at $+300{ }^{\circ} \mathrm{C}$, but a reduction in impact toughness of $c a$. $30 \mathrm{~J}$ below F690 at $-196{ }^{\circ} \mathrm{C}$.

The fracture surfaces of the failed specimens are presented in Figure 3 (F690 top, HIP690 bottom), with increasing temperature moving from left to right, and it is apparent that the HIP specimens generally exhibit a flatter topography over the entire temperature range. The effect is more pronounced at cryogenic temperatures than at elevated temperatures. To further highlight this, the lateral expansion of each specimen was measured at the maximum specimen width, in order to quantify and compare the extent of ductility between the specimens, and the data are presented in Figure 4 as a function of temperature for both materials. Lateral expansion was preferred over lateral contraction as a measure of ductility since it provided a larger delta from the $10 \mathrm{~mm}$ Charpy width, as shown in Figure 3.

For both materials, the degree of lateral expansion increases with increasing temperature. It could be suggested that HIP690 experiences a greater change in ductility at the different test temperatures, but the degree of data scatter is significant. Figure 5 shows how impact energy and lateral expansion are related, using all the test data from both materials and shows that as absorbed energy increases, the amount of plastic deformation accompanying ductile fracture also increases.

Figure 6 shows the engineering stress/strain test data for HIP690 and F690 at ambient and $-196{ }^{\circ} \mathrm{C}$. At both temperatures, HIP690 displays an increase in both yield stress $\left(\sigma_{Y}\right)$ and ultimate tensile strength (UTS) over F690, which is attributed to HIP690's finer grain size. ${ }^{[27]}$ The effect of temperature on dislocation mobility is reflected in the higher yield strength, UTS, and work hardening rate at cryogenic temperatures, and the continuous work hardening rate is indicative of a lack of martensitic phase transformation, unlike austenitic

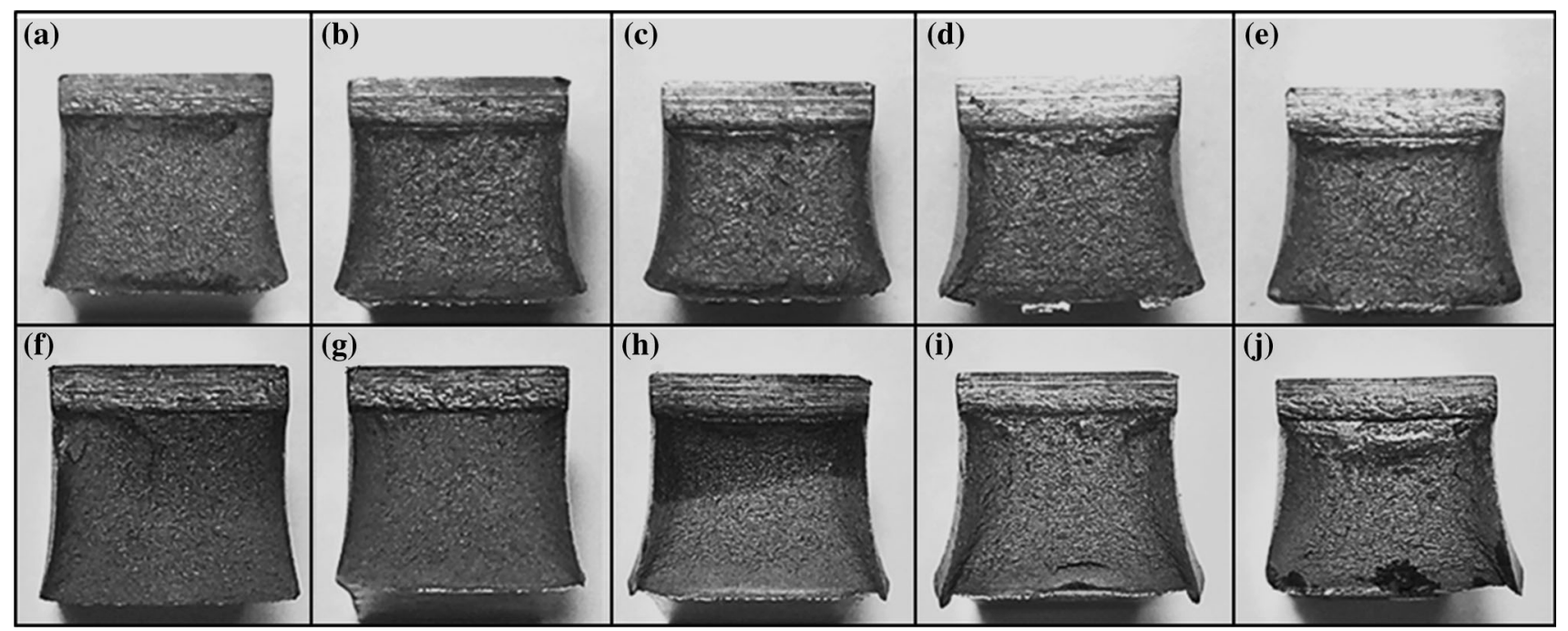

Fig. 3-F690 ( $a$ through $e$ ) and H690 ( $f$ through $j$ ) Charpy fracture surfaces after testing at $(\mathrm{a}, \mathrm{f}) 77 \mathrm{~K}\left(-196{ }^{\circ} \mathrm{C}\right),(\mathrm{b}, \mathrm{g}) 173 \mathrm{~K}\left(-100{ }^{\circ} \mathrm{C}\right),(\mathrm{c}$, h) $295 \mathrm{~K}\left(22{ }^{\circ} \mathrm{C}\right),(\mathrm{d}, \mathrm{i}) 473 \mathrm{~K}\left(200^{\circ} \mathrm{C}\right)$, and $(\mathrm{e}, \mathrm{j}) 573 \mathrm{~K}\left(300^{\circ} \mathrm{C}\right)$. 


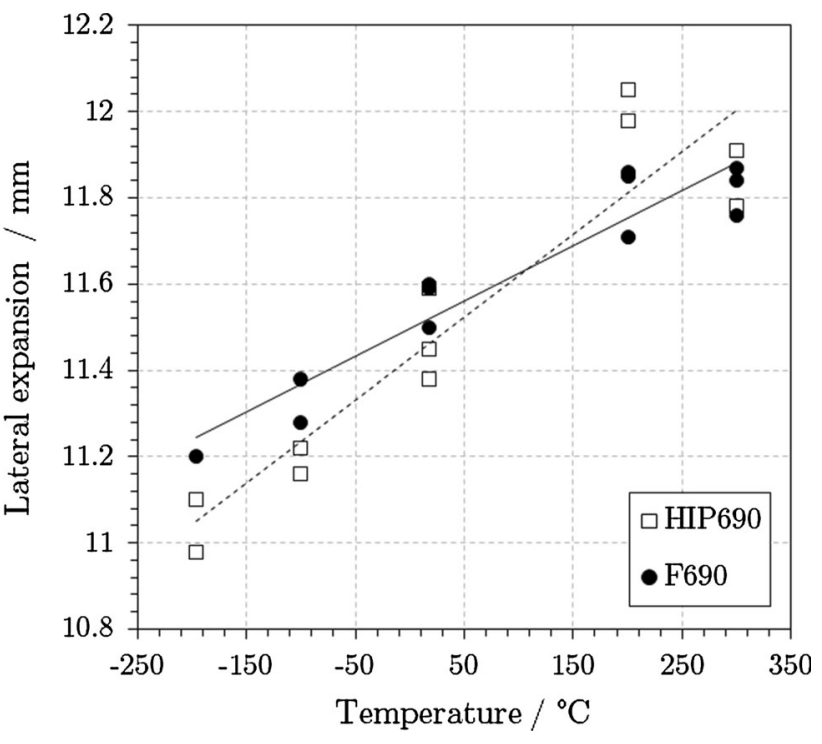

Fig. 4-Lateral expansion measurements for the failed Charpy specimens over the entire test temperature range.

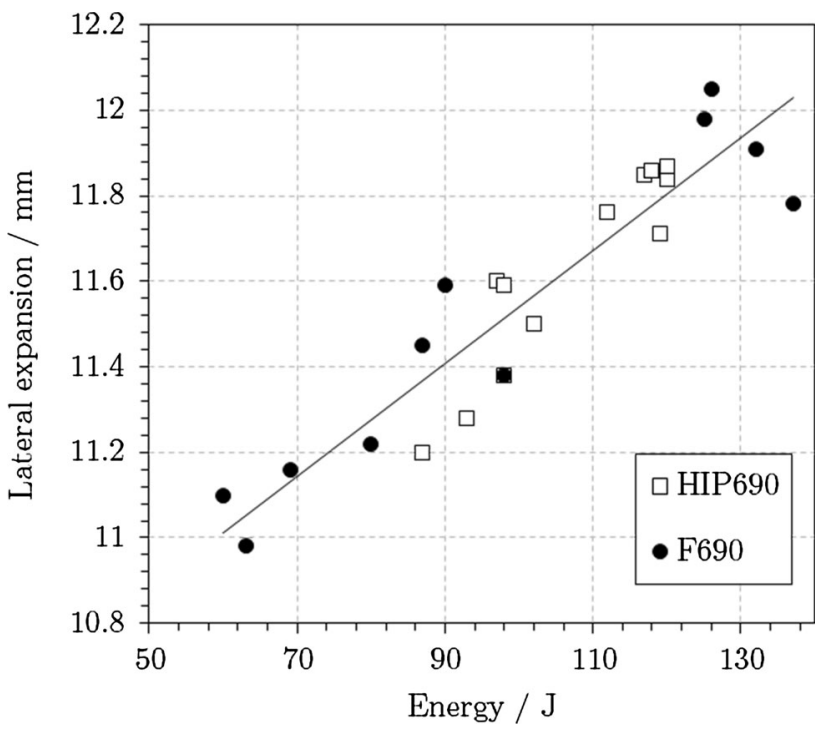

Fig. 5-Lateral expansion $v s$ energy for all specimens, indicating that the mechanism by which specimens absorb higher values of energy is through lateral contraction.

steels which undergo martensitic transformation and a two-stage hardening transition in the strain hardening behavior. ${ }^{[28]}$

Results for yield stress, UTS, elongation pct, and reduction in area (RA pct) obtained from tensile testing are presented in Table II, where HIP690 displays enhanced yield and UTS at both temperatures.

Instrumented Charpy testing was performed at ambient and elevated temperature in order to observe the load/displacement behavior across the entire temperature range since elevated tensile testing was not possible for this work: the load-displacement traces are presented in Figure 7 showing results at ambient and $300{ }^{\circ} \mathrm{C}$. At elevated temperature testing (red lines),

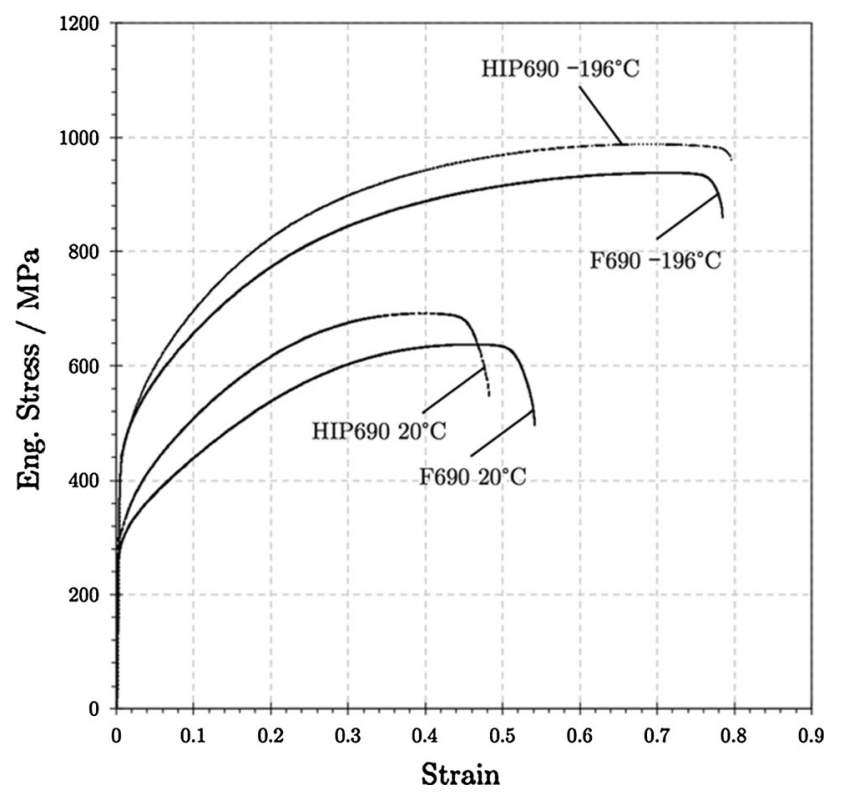

Fig. 6-Engineering stress/strain curves for HIP690 and F690 at ambient (black) and $-196{ }^{\circ} \mathrm{C}$ (blue).

HIP690 displays an enhanced absorbed energy, which is equivalent to the area below the load/displacement trace, and it can be seen that this increase in area is mainly a result of the increased peak load. The total displacement is slightly smaller for HIP690 than for F690 (14 $\mathrm{mm}$ cf. $20 \mathrm{~mm}$ ), though the area under the curve is small compared to the effect of HIP690's increased load over the initial 13-mm displacement.

At ambient temperature, HIP690 displays a higher peak load, but smaller overall displacement than F690, resulting in a comparable absorbed energy. These observations are consistent with the Charpy impact toughness values in Figure 2, which show HIP690 exhibiting higher toughness than F690 at elevated temperature and similar toughness values at ambient temperature.

Figure 8 shows the fracture surfaces of failed $(a, b)$ F690 and (c, d) HIP690 Charpy specimens tested at (a, c) $-196{ }^{\circ} \mathrm{C}$ and $(\mathrm{b}, \mathrm{d}) 300^{\circ} \mathrm{C}$. The figures shown were regions within $c a .1 \mathrm{~mm}$ of the Charpy V-notch tip in the center of the specimens and were deemed representative of the entire fracture surface since the same observations were made over several analysis areas. It can be seen that the characteristic ductile dimpling associated with microvoid coalescence differs in dimple size for the two materials: whereas F690 exhibits a network of large voids with diameters on the order of $50 \mu \mathrm{m}$, connected by regions of much finer ductile dimpling, HIP690 exhibits a much finer network of ductile void growth with diameters on the order of $1 \mu \mathrm{m}$. The size and void network characteristics of the two materials appear to be unaffected by test temperature. The HIP fracture surface appears to be much more homogenous, which is consistent with the material's microstructure and manufacture route. These fracture surface characteristics are similar in appearance to stainless steel specimens previously reported by the authors, ${ }^{[15]}$ whereby HIP'd 
Table II. Tensile Properties

\begin{tabular}{lll}
\hline & F690 & H690 \\
\hline $20{ }^{\circ} \mathrm{C}$ & & \\
SigY & $270 \mathrm{MPa}$ & $302 \mathrm{MPa}$ \\
UTS & $638 \mathrm{MPa}$ & $692 \mathrm{MPa}$ \\
EL Pct & 54 & 48 \\
RA Pct & 38 & 39 \\
\hline & F690 & \\
\hline & & \\
\hline $196{ }^{\circ} \mathrm{C}$ & $428 \mathrm{MPa}$ \\
SigY & $938 \mathrm{MPa}$ & $448 \mathrm{MPa}$ \\
UTS & 78 & $988 \mathrm{MPa}$ \\
EL Pct & 34 & 30 \\
RA Pct & & 30 \\
\hline
\end{tabular}

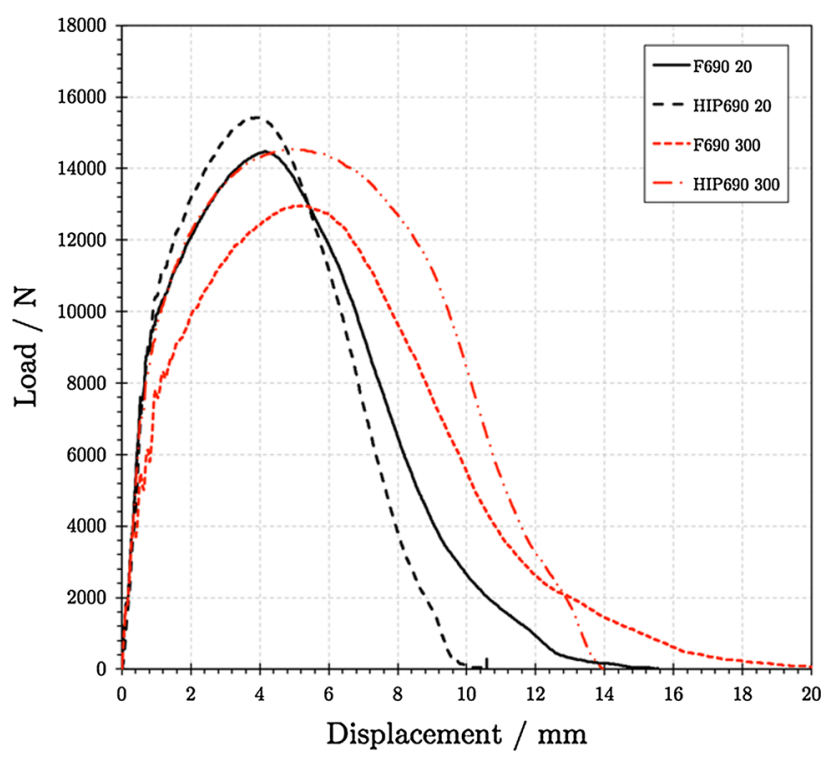

Fig. 7-Instrumented Charpy load/displacement traces for HIP'd and forged Inconel 690 tested at ambient temperature and $300{ }^{\circ} \mathrm{C}$.

stainless steel exhibited a much finer network of ductile dimpling compared to forged stainless steel. Figure 9 shows high-resolution secondary electron SEM images of the fracture surfaces of (a) F690 and (b) HIP690 tested at $77 \mathrm{~K}\left(-196{ }^{\circ} \mathrm{C}\right)$ that were deemed representative of the entire fracture surface. Again it is clear that the average size of the ductile dimples is significantly larger in F690 than in HIP690, and the initiating particles from which the voids grow are also identifiable. The initiating particles found in F690 were large enough to be analyzed by EDS, revealing that the void-initiating particles were predominantly rich in titanium and nitrogen and exhibited a similar chemical composition to those shown previously in the microstructure of F690 (Figure 1(e)). The brittle nature of these TiN particles is highlighted by the shear fracture of a number of particles in Figure 9(a). Conversely, the initiating particles in HIP690 were fine and similar in characteristics to the oxide particles shown in Figure 1(f). Again, these particles were too small to be accurately analyzed by EDS, but did reveal prominent peaks associated with aluminum, silicon, sulfur, and oxygen, heavily suggesting that they are oxide particles in nature.

Given the evidence to suggest a greater number and closer spacing of oxide inclusions in the HIP690 microstructure (Figure 1), together with the higher oxygen content of the HIP'd Inconel 690 over F690 (230 ppm cf. $17 \mathrm{ppm}$ ) and finer ductile dimpling on the fracture surface of test specimens (Figure 8), it seems likely that the ductile fracture mechanism is similar to that previously observed for stainless steel studies ${ }^{[15]}$ as described in Section I.

\section{DISCUSSION}

HIP'd and forged variants of Inconel 690 have been shown to exhibit subtle differences in Charpy impact toughness, over the temperature range of $-196{ }^{\circ} \mathrm{C}$ to $300{ }^{\circ} \mathrm{C}$ (Figure 2). Martensitic transformation was shown to occur at the tip of the Charpy V-notch in type 300 steels at depreciated temperatures, ${ }^{[16]}$ and together with this study we offer two scenarios whereby martensitic transformation is both included (300 stainless steel) and omitted (Inconel 690) from the deformation mechanism. In all cases (previously reported stainless studies and present Inconel 690 studies), the impact toughness was lower for the HIP'd variants of the alloys when testing at temperatures below ambient temperature. However, one notable difference arises between the stainless steel studies and Inconel when considering the gradients of the data trends: a reduction in temperature appears to have a greater detrimental effect on HIP690 impact toughness than it does for F690. This is in contrast to previous work on stainless steel, whereby the reduction in toughness with temperature appeared comparable for HIP'd and forged variants. $^{[15]}$

This difference in gradient, observed in Figure 2, results in HIP690 displaying enhanced impact toughness over F690 when the test temperature is raised to temperatures exceeding $100{ }^{\circ} \mathrm{C}$, in contrast to type 300 steels where forged variants of $304 \mathrm{~L}$ and $316 \mathrm{~L}$ consistently exhibited higher toughness over HIP steels at any test temperature. This can be understood by considering stainless steel's superior ductility, which is reflected in the incomplete fracture of Charpy specimens exiting the anvils prior to complete fracture due to the extensive plastic deformation of the specimens. ${ }^{[15]}$ Unlike stainless steel, where differences in impact toughness between HIP'd and forged variants of $316 \mathrm{~L} / 304 \mathrm{~L}$ were indiscernible at elevated temperature due to incomplete failure of test specimens, ${ }^{[15,16]}$ here all the Inconel 690 Charpy specimens exhibited complete fracture (Figure 3), and it can be concluded that HIP'd Inconel 690 exhibits higher toughness than F690 at temperatures greater than $c a .100{ }^{\circ} \mathrm{C}$, but lower impact toughness at cryogenic temperature testing.

Unlike brittle failure, which can be accurately quantified through statistical approaches such as the master curve, ${ }^{[29]}$ there is currently no unified quantitative theory 

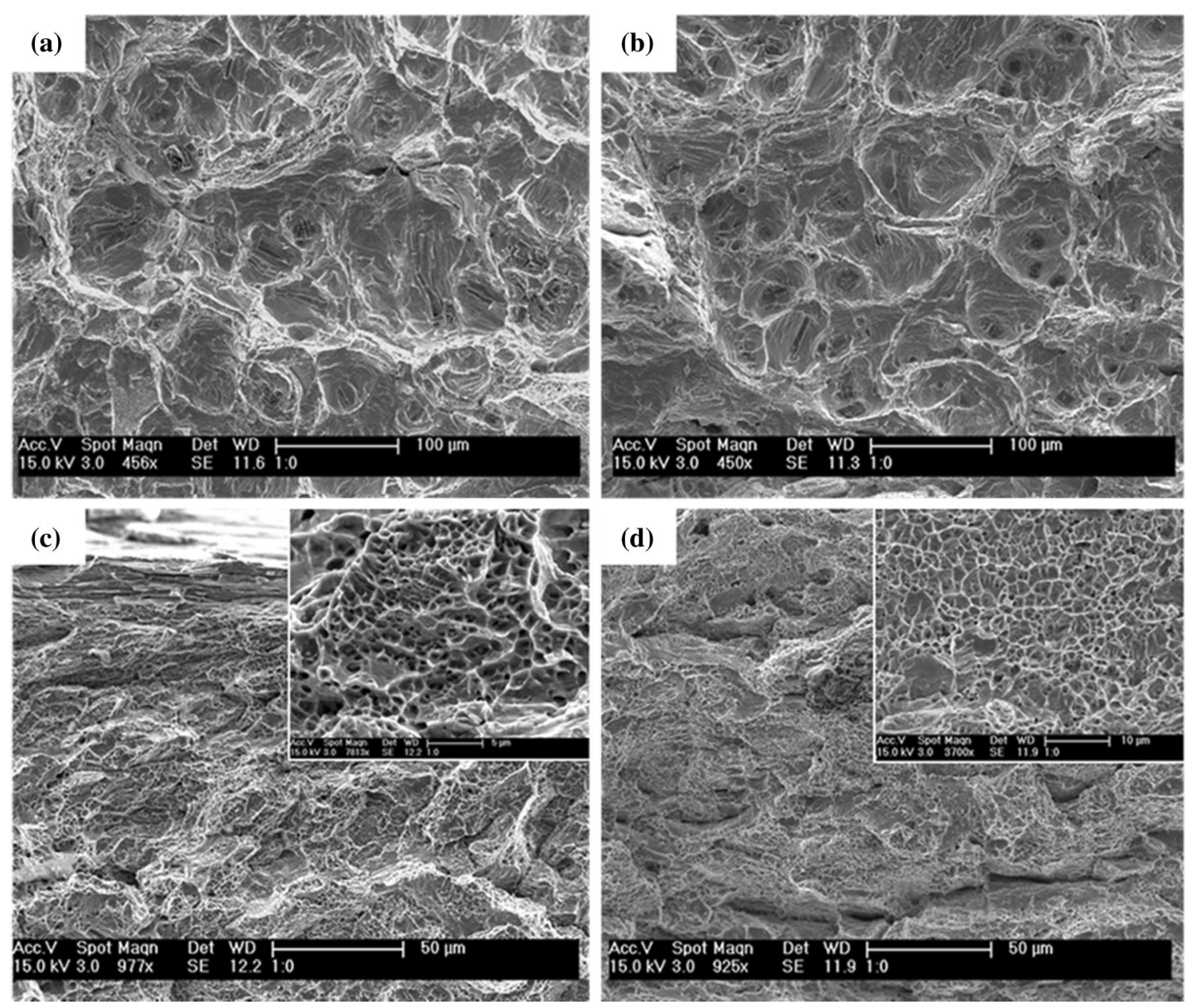

Fig. 8-Fracture surface secondary electron images of (a) F690 at $77 \mathrm{~K}\left(-196{ }^{\circ} \mathrm{C}\right),(b) \mathrm{F} 690$ at $573 \mathrm{~K}\left(300{ }^{\circ} \mathrm{C}\right),(c) \mathrm{HIP} 690$ at $77 \mathrm{~K}\left(-196{ }^{\circ} \mathrm{C}\right)$, and $(d)$ HIP690 at $573 \mathrm{~K}\left(300{ }^{\circ} \mathrm{C}\right)$.

that can quantify the fracture toughness of steels that fail via the nucleation, growth, and coalescence of microvoids. ${ }^{[30]}$ Several semi-quantitative approaches have been developed, ${ }^{[31-37]}$ from which it has been established that yield strength, elongation, strain to failure, and the particle spacing at which voids can nucleate all contribute to a material's fracture toughness and follow the general form of $K_{\mathrm{IC}} \propto \sqrt{E \varepsilon_{\mathrm{f}} \sigma_{\mathrm{y}} l_{0}},{ }^{[30,38]}$ where $K_{\mathrm{IC}}$ is the equivalent fracture toughness, $\varepsilon_{\mathrm{f}}$ is the strain at failure, $E$ is Young's modulus, $\sigma_{\mathrm{y}}$ is the yield strength, and $l_{0}$ is a characteristic distance comparable to the mean spacing of the void-initiating particles.

The interaction between strength, elongation, and strain hardening can be demonstrated through the use of Considère's criterion ${ }^{[39]}$ which defines plastic instability (necking) as the point at which the rate of increasing true stress, as a result of decreasing cross-sectional area, becomes greater than the rate of increasing load-bearing capacity, due to strain hardening, and localised deformation occurs, i.e., $\frac{\mathrm{d} \sigma}{\mathrm{d} \varepsilon}=\sigma$. As a consequence of Considère's criterion, whereby necking strain decreases monotonically with increasing yield strength, fracture toughness actually decreases with increasing yield strength at a given temperature. ${ }^{[30,40]}$ Furthermore, ductile failure models, which include the inclusion content, predict that the inclusion spacing has a much stronger influence on the fracture toughness as yield strength increases, suggesting that the effect of inclusion spacing should be more pronounced at lower temperatures. ${ }^{[30]}$

At cryogenic temperatures, yield strength increases because plastic deformation is energetically less favorable, since dislocation mobility is severely hindered, and plasticity only occurs locally ahead of the notch tip, where the applied stress is sufficiently high to overcome this mobility barrier. Thus, the dominating mechanism of energy absorption is localised in the form of void growth and coalescence in the direction of maximum plastic strain ahead of the notch, and crack growth occurs with a minimal degree of macro-scale plasticity in the specimen ligaments. This is revealed in CTOD testing of fracture mechanics specimens, in which the plastic component of notch opening displacement, $V_{\mathrm{p}}$, decreases with decreasing temperature, while the elastic component remains relatively constant. ${ }^{[40]}$ If we assume void coalescence is more energetically favorable in HIP690 than F690, as a result of smaller spatial distances between voids due to the oxide spacings, then it follows that HIP690 should exhibit lower Charpy toughness than F690 at cryogenic temperatures. 

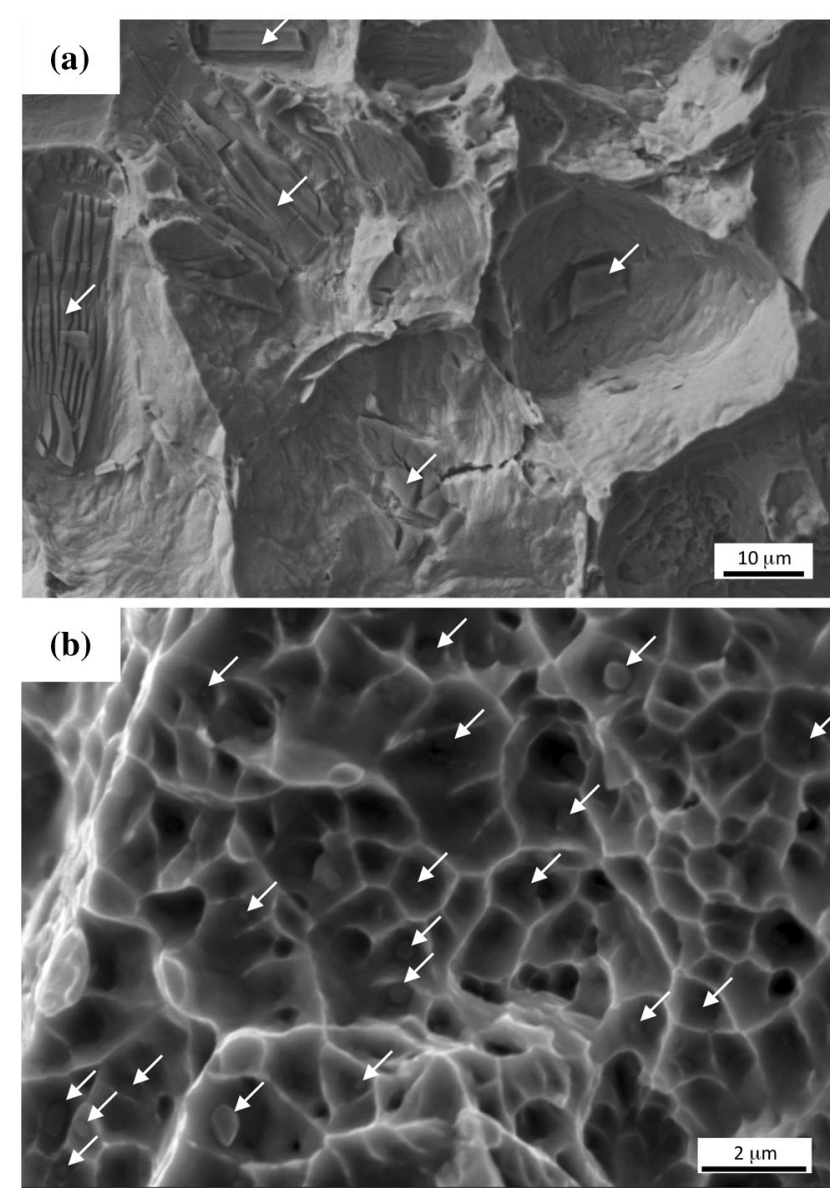

Fig. 9-High-resolution secondary electron SEM images of the fracture surfaces of (a) F690 and (b) HIP690 tested at $77 \mathrm{~K}\left(-196{ }^{\circ} \mathrm{C}\right)$, highlighting the presence of initiating particles: titanium nitride particles in F690 and finer oxide particles in HIP690.

However, as the temperature increases, energy absorbed via microvoid coalescence is accompanied by a second mode of energy absorption: plastic deformation in the ligaments of the Charpy specimens as a result of decreasing yield strength. Because the plastic zone is now sufficiently large and extends into the ligaments of the Charpy test specimen, mechanisms that affect material strength and work hardening behavior such as grain size and interstitial alloying elements (such as carbon and nitrogen) are now able to exert a greater influence on the overall energy absorption mechanism. However, as the temperature increases and dislocations gain energy, their newly promoted mobility is simultaneously met with an increased resistance provided by grain boundaries (yield strength increases with decreasing grain size at a given temperature); this greater resistance in HIP690 is attributed to HIP690's finer microstructure and higher nitrogen concentration (both well-known strengthening mechanisms ${ }^{[41-43]}$, and therefore as the temperature increases, HIP690 absorbs more energy than F690 during impact. Alternatively, although increasing temperature decreases yield strength and promotes plastic deformation, as the plastic zone encompasses a greater volume of material, grain size effects become more dominant, thereby hindering dislocation mobility and having an increasing effect on work hardening. The difference in grain size could therefore account for the different gradients in Figure 2.

The effect of test specimen geometry and crack tip constraint is highlighted in recent fracture toughness testing of $316 \mathrm{~L}$ stainless steel-welded joints ${ }^{[44,45]}$ which display a marked reduction in fracture toughness at elevated temperature compared to ambient temperature testing, in contrast to the improved impact toughness with increasing temperature gleaned from the Charpy impact testing both herein and previously. ${ }^{[15,16]}$

The effect of constraint becomes noticeable once the temperature is sufficiently high $\left(>100{ }^{\circ} \mathrm{C}\right)$ to generate a large enough plastic zone ahead of the notch, which dwarfs the local void growth/coalesce effects caused by the smaller distances over which voids are required to grow to coalesce, and can explain why HIP690 exhibits higher Charpy toughness than F690 at elevated temperature. The Charpy impact toughness is therefore a play-off between (a) the energy associated with the local void growth and coalescence (fracture) mechanism, governed by initiating particle distributions, and (b) macro-scale plastic deformation in the specimen ligaments, governed by dislocation mobility.

This difference in global and local material behavior is further highlighted in the tensile test data shown in Figure 6, which suggest that HIP690 displays improved strength and equivalent ductility to F690 at cryogenic testing despite exhibiting lower impact toughness to F690 at this temperature. This phenomenon is observed because the tensile test results are representative of the entire test specimen gage length (the plastic zone extends throughout the entire gage length), whereby material strength and work hardening rate both increase with decreasing temperature, ${ }^{[30]}$ showing behavior akin to the high-temperature Charpy test specimens, which also experience large-scale global plasticity.

This underlines the challenging nature of obtaining definitive mechanistic information of ductile fracture from Charpy testing of tough materials, since the total absorbed impact energy is a complex combination of the local ductile fracture process and plastic deformation in the specimen ligaments. Since this observation is an inherent consequence of the Charpy test specimen geometry and loading conditions (low constraint and large plastic zone), it is thought that high-constraint fracture toughness testing would result in HIP690 exhibiting a lower fracture toughness than F690 at elevated temperature testing, since the specimen geometry, crack, and loading conditions are designed to maintain a high level of triaxiality at the crack tip by constraining the plastic zone, thereby maintaining a localised ductile fracture process. This has been observed when performing fracture toughness testing of HIP's and forged 304L at elevated temperature (see supplementary information and Reference 16), whereby HIP304L displayed both a lower $J$ initiation toughness $\left(J_{0.2 \mathrm{BL}}\right)$ and lower resistance to ductile crack growth despite exhibiting higher strength and equivalent Charpy impact toughness at $300^{\circ} \mathrm{C}$.

The lower Charpy impact toughness observed in HIP'd austenitic stainless steel $c f$. forged stainless steel is 
attributed to the presence of a comparatively large volume fraction of non-metallic oxide inclusions in the steel microstructure, resulting from powder surface oxidation during powder handling and storage, which act as additional sites for ductile void nucleation; it is the same mechanism as observed in stainless steel. However, at $-196{ }^{\circ} \mathrm{C}$, HIP690 (containing $210 \mathrm{ppm}$ oxygen) exhibits a reduction in toughness of $c a .30$ pct when compared to F690 (17 ppm oxygen). This is in contrast to the HIP316L (190 ppm oxygen) exhibiting a reduction in impact toughness of $c a$. 70 pct when compared to F316L (23 ppm) at the equivalent test temperature. ${ }^{[15]}$ If oxygen is directly linked to impact toughness, this appears counterintuitive, since HIP690 contains a higher oxygen concentration than HIP316L, yet exhibits a smaller percentage reduction in toughness at $-196{ }^{\circ} \mathrm{C}$.

However, although both materials are FCC, there are likely to be significant differences in the size of the accommodating lattice vacancies, governed by the different atomic radii of nickel, chromium, and iron as well as the ratio of the alloying elements. The solubility of oxygen in pure austenite has been reported to be on the order of $<30 \mathrm{ppm},{ }^{[46,47]}$ and any increase in the solid solubility of oxygen in the $\mathrm{Cr}-\mathrm{Ni}$ matrix could decrease the volume fraction of oxide inclusions formed in the microstructure. Quantitative comparisons of Charpy impact toughness data at specific temperatures between Inconel 690 and type 300 steels are further complicated by the Inconel materials' different thermal treatments, with the HIP material being tested in the as-HIP'd condition and the forged 690 undergoing a solution annealing.

Despite these complications, the fracture surfaces of the Charpy specimens (Figure 3) indicate that the fracture mechanism is unchanged across the entire temperature range; ductile dimpling associated with the coalescence of neighboring ductile voids is clearly visible on the fracture surfaces and the two materials display different populations of dimple sizes. F690 fracture surfaces are constructed from large voids with diameters on the order of 50 to $100 \mu \mathrm{m}$, which originate at large titanium nitride particles (Figure 9(a)), linked together via a secondary network of finer voids, thought to initiate at smaller nitride particles such as those observed in the microstructure of F690 (Figure 1(e)), whereas HIP690 displays a single population of coalesced voids having diameters on the order of microns which initiate at fine oxide particles shown here both in the initial microstructure (Figure 1(f)) and within the ductile dimples on the fracture surfaces (Figure 9(b)). These observations are in agreement with those previously reported for $316 \mathrm{~L},{ }^{[15]}$ suggesting that the previously reported mechanism is not restricted to stainless steel, but to nickel superalloys also, and strengthens the argument for the need of limits on the oxygen concentration remaining in the microstructure post HIP.

Despite the undesirable differences in grain size and thermal treatment between HIP'd and forged Inconel 690, which complicate the quantitative analyses of Charpy impact toughness values at specific temperatures for different materials, this study establishes that martensitic transformation does not play a significant role in lowering toughness of HIP materials when compared to equivalently graded forged nickel superalloys. In the same fashion as austenitic stainless steel, the mechanism is governed instead by the presence and interspatial distance of oxide inclusions, which require smaller plastic strains in order to coalesce with neighboring voids.

Finally, it is important to stress that hot isostatic pressing continues to be a viable and promising manufacture route to structural components and produces materials that easily exceed minimum specification code requirements with regard to strength and toughness, as demonstrated by Burdett and co-workers. ${ }^{[6,27,48,49]}$ Our recent work is not intended to discourage or undermine the development of HIP technology but aims to highlight the subtly different ductile failure mechanism in HIP'd and forged variants of equivalent grade material. Although minimum impact toughness specifications are normally safely exceeded with HIP materials, not maintaining proper control over the oxygen concentration can drastically reduce impact and fracture toughness to below minimum specification code requirements. Although this may appear obvious, oxygen concentrations are currently not stated in material certificates for materials manufactured by HIP.

\section{CONCLUSIONS}

The aim of this study was to test an ongoing hypothesis on the ductile failure of HIP'd and forged steels on a material that does not undergo martensitic transformation, thereby eliminating the effects of martensitic transformation from the fracture mechanics investigation. We have concluded the following:

(1) The effects of oxygen on impact toughness of Inconel 690 are comparable those of type 300 stainless steels.

(2) Strain-induced martensitic transformation is not believed to play a significant role in reducing the impact toughness of HIP materials, and the mechanism is dominated instead by the presence (and interspatial distance) of oxide inclusions which act as initiation sites for the nucleation of voids.

(3) The mechanism by which oxygen causes a reduction in impact toughness is not material dependant and is thought to apply to any ductile material where the oxygen solid solution solubility limit is exceeded.

\section{ACKNOWLEDGMENTS}

We would like to thank the UK EPSRC for funding this research project. We are grateful to $\mathrm{Mr}$. Adam Bannister and Mr. Stuart Sotheran at Tata Steel for measurement of Charpy data, as well as EPRI and 
N-AMRC for the provision of materials. We also appreciate the efforts of the MTC for chemical analysis.

\section{OPEN ACCESS}

This article is distributed under the terms of the Creative Commons Attribution 4.0 International License (http://creativecommons.org/licenses/by/4.0/), which permits unrestricted use, distribution, and reproduction in any medium, provided you give appropriate credit to the original author(s) and the source, provide a link to the Creative Commons license, and indicate if changes were made.

\section{ELECTRONIC SUPPLEMENTARY MATERIAL}

The online version of this article (https://doi. org/10.1007/s11661-017-4465-3) contains supplementary material, which is available to authorized users.

\section{REFERENCES}

1. H.V. Atkinson and S. Davies: Metall. Mater. Trans. A., 2000, vol. 31, pp. 2981-3000.

2. C. Barre: Adv. Mater. Process., 1999, vol. 155, pp. 47-48.

3. A.S. Helle, K.E. Easterling, and M.F. Ashby: Acta Metall., 1985, vol. 33, pp. 2163-74.

4. Y.C. Jeon and K.T. Kim: Int. J. Mech. Sci., 1999, vol. 41, pp. $815-30$

5. G.A. Rao and M. Kumar: Mater. Sci. Technol., 1997, vol. 13, pp. 1027-31.

6. W.B. Burdett, P. Hurrell and A. Gilleland: In American Society of Mechanical Engineers, Pressure Vessels and Piping Conference Proceedings, (2004), pp 153-60.

7. H.T. Larker and R. Lundberg: J. Eur. Ceram. Soc., 1999, vol. 19, pp. 2367-73.

8. M.N. Chandrasekharaiah: Sadhana, 1995, vol. 20, pp. 213-32

9. J.F. Lancaster: Metallurgy of Welding, Elsevier, London, 1999.

10. W.J. Brayshaw, A.H. Sherry, M.G. Burke and P. James: American Society of Mechanical Engineers, Pressure Vessels and Piping Conference Proceedings 2016, pp. PVP2016-63045.

11. J.-S. Kim, B.-Y. Lee, W.-G. Hwang and S.-S. Kang: Adv. Mater. Sci. Eng. 2015, vol. 2015.

12. S. Ghosh, V.P.S. Rana, V. Kain, V. Mittal, and S.K. Baveja: Mater. Des., 2011, vol. 32, pp. 3823-31.

13. G. Byrne, M.A. Spence, B. Olsen, P.J. Houghton and J. McMahon: TWI Paper 191994.

14. S. Irukuvarghula, H. Hassanin, C. Cayron, M.M. Attallah, D. Stewart, and M. Preuss: Acta Mater., 2017, vol. 133, pp. 269-81.

15. A.J. Cooper, N.I. Cooper, J. Dhers, and A.H. Sherry: Metall. Mater. Trans. A, 2016, vol. 47, pp. 4467-75.

16. A.J. Cooper, N.I. Cooper, A. Bell, J. Dhers, and A.H. Sherry: Metall. Mater. Trans. A, 2015, vol. 46, pp. 5126-38.

17. A.J. Cooper, J. Dhers and A.H. Sherry: American Society of Mechanical Engineers, Pressure Vessels and Piping Conference Proceedings 2016, pp. PVP2016-63033.

18. A.J. Cooper, T.L. Burnett and A.H. Sherry: Draft Manuscript 2017.
19. D.L. Saraiva, M. Béreš, C.C. Silva, C.S. Nunes, J.J.M. Silva, and H.F.G. Abreu: Mater. Sci. Technol., 2014, vol. 30, pp. 1057-62.

20. G.A. Rao, M. Srinivas, and D.S. Sarma: Mater. Sci. Eng. A, 2006, vols. 435-436, pp. 84-99.

21. ASTM B168-11: Standard Specification for Nickel-Chromium-Iron Alloys (UNS N06600, N06601, N06603, N06690, N06693, N06025, N06045, and N06696). (ASTM International, West Conshohocken, PA, 2016).

22. ASTM E112-96: Standard Test Methods for Determining Average Grain Size. (ASTM International, West Conshohocken, PA, 1996).

23. BS EN ISO 148-1:2010 Metallic Materials. Charpy pendulum impact test. Test method. (2010).

24. ASTM E3-01: Standard Practice for Preparation of Metallographic Specimens. (ASTM International, West Conshohocken, PA, 2001).

25. ASTM E8/E8M: Standard Test Methods for Tension Testing of Metallic Materials. (ASTM International, West Conshohocken, PA, 2010)

26. J. Tan, X. Wu, E. Han, W. Ke, X. Liu, F. Meng, and X. Xu: Corros. Sci., 2014, vol. 88, pp. 349-59.

27. T.C. Jelfs and W.B. Burdett: American Society of Mechanical Engineers, Pressure Vessels and Piping Division (Publication) PVP 2011, pp. PVP2011-57194.

28. T.S. Byun, N. Hashimoto, and K. Farrell: Acta Mater., 2004, vol. 52, pp. 3889-99.

29. K. Wallin: Eng. Fract. Mech., 2002, vol. 69, pp. 451-81.

30. J.W. Morris: Steels for Low Temperature Applications, Technical Report, Lawrence Berkley Laboratory-University of California, 1993.

31. F.M. Beremin: Proceedings of the IUTAM Symposium on Three-Dimensional Constitutive Relations and Ductile Fracture, 1981.

32. M.G. Cockcroft and D.J. Latham: J. Inst. Metals, 1968, vol. 96, pp. 33-39.

33. F.A. McClintock: J. Appl. Mech., 1968, vol. 35, pp. 363-71.

34. M. Oyane, T. Sato, K. Okimoto, and S. Shima: J. Mech. Work. Technol., 1980, vol. 4, pp. 65-81.

35. J.R. Rice and D.M. Tracey: J. Mech. Phys. Solids, 1969, vol. 17, pp. 201-17.

36. V. Tvergaard and A. Needleman: Acta Metall., 1984, vol. 32, pp. 157-69.

37. M. Rakin, Z. Cvijovic, V. Grabulov, S. Putic, and A. Sedmak: Eng. Fract. Mech., 2004, vol. 71, pp. 813-27.

38. R.O. Ritchie and A.W. Thompson: Metall Trans A, 1985, vol. 16, pp. 233-48.

39. M. Considère: Annales des Ponts et Chaussees, 1885, vol. 9, pp. $574-775$.

40. J.-H. Baek, Y.-P. Kim, W.-S. Kim, and Y.-T. Kho: KSME Int. J., 2002, vol. 16, pp. 1064-71.

41. K.J. Irvine, T. Gladman, and F.B. Pickering: J. Iron Steel Inst., 1969, vol. 207, pp. 1017-28.

42. K. Kako, E. Kawakami, J. Ohta, and M. Mayuzumi: Mater. Trans., 2002, vol. 43, pp. 155-62.

43. F. Pickering: Materials Science and Technology, Wiley-VCH Verlag $\mathrm{GmbH} \& \mathrm{Co} . \mathrm{KGaA}$, Weinheim, 2006.

44. W. Gao, K. Chen, X. Guo, and L. Zhang: Mater. Sci. Eng. A, 2017, vol. 685, pp. $107-14$

45. C. Picker: The fracture toughness of type 316 steel and weld metal, UKAEA Working Group on Fast Reactors (IWGFR-49). Specialist Meeting on Mechanical Properties of Structural Materials Including Environmental Effects 1983.

46. J.A. Kitchener, J.M. Bockris, M. Gleiser, and J.W. Evans: Acta Metall., 1953, vol. 1, pp. 93-101.

47. J.A. Kitchener, J.M. Bockris, M. Gleiser, and J.W. Evans: Trans. Faraday Soc., 1952, vol. 48, pp. 995-97.

48. W.B. Burdett: American Society of Mechanical Engineers, Pressure Vessels and Piping Conference Proceedings 2006, pp. PVP2006-ICPVT-11-93139, pp. 255-60.

49. W.B. Burdett: American Society of Mechanical Engineers, Pressure Vessels and Piping Conference Proceedings 2010, pp. PVP2010-25209, pp. 815-20. 